Канд. техн. наук О.В. Братченко

\title{
ОСОБЛИВОСТІ АНАЛІТИЧНОГО ДОСЛІДЖЕННЯ КІНЕМАТИЧНИХ ХАРАКТЕРИСТИК МЕХАНІЧНОЇ СИСТЕМИ РЕГУЛЮВАННЯ ШВИДКОСТІ ДИЗЕЛЬ-ПОЇЗДУ ДР1А
}

\author{
Представив д-р техн. наук, професор В.І. Мороз
}

\begin{abstract}
Постановка задачі та аналіз останніх результатів досліджень. Відповідно до основних положень діючих Державних і цільових програм пріоритетним напрямком заходів 3 оновлення рухомого складу (РС) $\epsilon$ забезпечення залізниць України парком РС переважно нового покоління. Це дозволить покращити техніко-економічні показники діяльності залізничного транспорту, поліпшити безпеку та зручність перевезень, підвищити конкурентоспроможність залізниць України, суттєво підвищити ефективність роботи галузі. В той же час оновлення залізничного РС пов'язане зі значними термінами впровадження i потребує дуже великих витрат коштів. Тому при поетапному вирішенні такої проблеми актуальними є роботи, спрямовані на зниження витрат щодо утримання наявного РС в експлуатації.

Великий обсяг пасажироперевезень на неелектрифікованих дільницях
\end{abstract}

приміських сполученнях здійснюється дизель-поїздами ДР1А (ДП ДР1А) [1, 2], більша частина яких експлуатується у наднормативний термін. Наукові дослідження [3, 4] та досвід експлуатації дизель-поїздів показали, що одним 3 перспективних напрямків досягнення високого рівня експлуатаційних показників ДП ДР1А $є$ поліпшення їх тягових характеристик за рахунок скорочення часу на розгін поїзда при зрушенні i наборі швидкості, особливо за початковими позиціями контролера машиніста $[5,6]$.

Практична реалізація зазначеного потребує удосконалення конструкції механічної системи регулювання швидкості ДП ДР1А, основою якої $\epsilon$ просторовий механізм управління регулятором частоти обертів (РЧО) колінчатого вала силової установки. При цьому при проведенні пошукових досліджень особливої актуальності набувають розрахунки кінематичних характеристик ланок РЧО, 
які можуть бути проведені на основі відповідних аналітичних досліджень.

Аналіз останніх досліджень i публікацій показав, що питання отримання і використання аналітичних описань зміни кінематичних характеристик просторової механічної системи регулювання швидкості ДП ДР1А в сучасній науково-технічній літературі висвітлені не достатньо.

Мета статті і викладення основного матеріалу. Метою статті $\epsilon$ викладення особливостей аналітичного дослідження кінематичних характеристик механічної системи регулювання швидкості ДП ДР1А 3 просторовим механізмом управління РЧО, яке проводилось 3 використанням методу проекцій замкнених векторних контурів на осі координат [7].

Особливості аналітичного дослідження кінематичних характеристик механічної системи регулювання швидкості дизель-поїзда ДР1А. На першому етапі досліджень було уточнено кінематичну схему серійного механізму управління РЧО (рис. 1). До кінематичного ланцюга важільного механізму управління РЧО входять такі ланки: 1 - повзун; 2 шатун; 3 - важіль керування тягою холостого ходу (кут розвалу плечей $\left.\alpha=90^{\circ}\right) ; 4$ - тяга холостого ходу; 5 пусковий важіль (кут розвалу плечей $\beta=180^{\circ}$ ); 0 - стояк (корпус механізму).

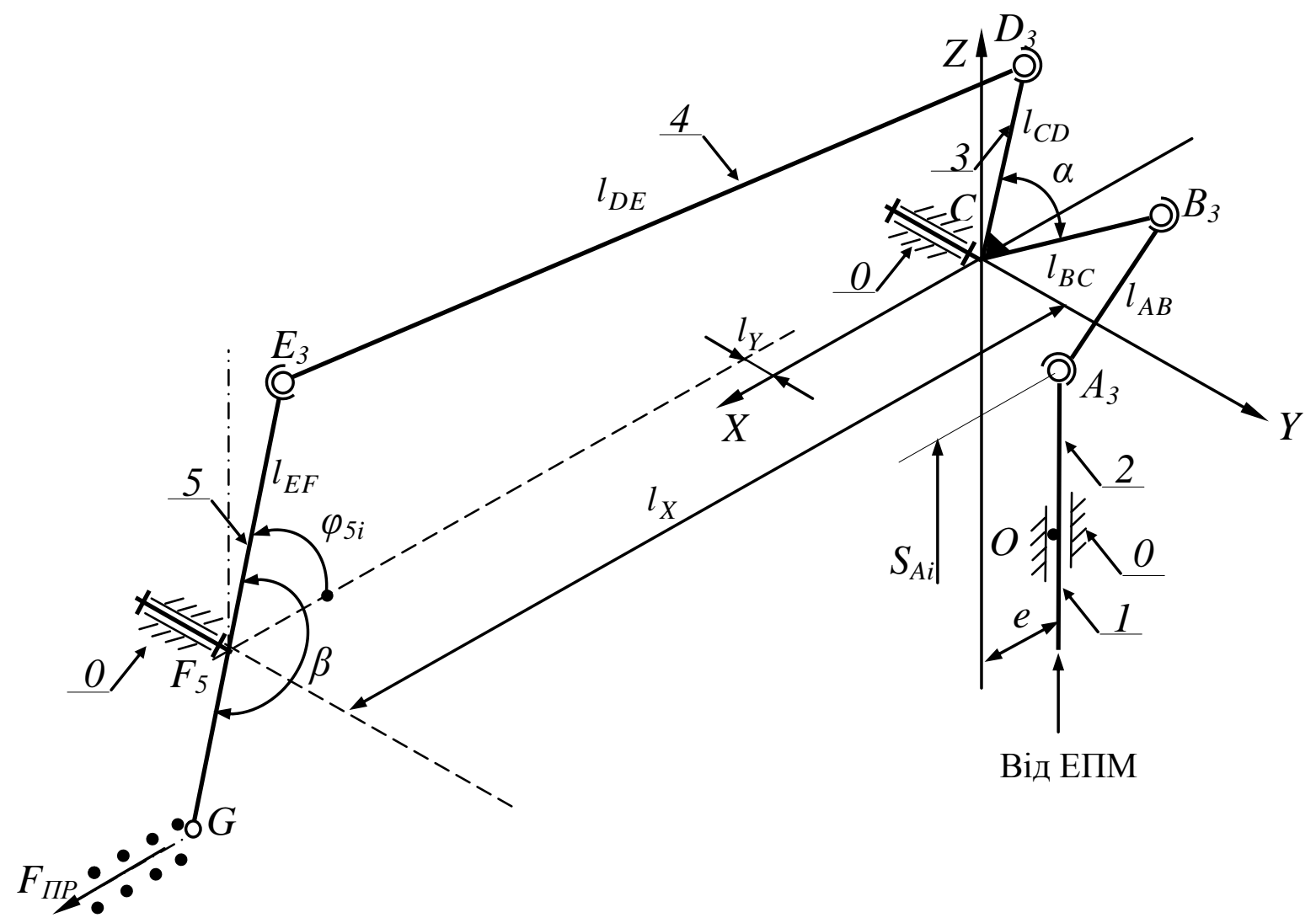

До всережимної

пружини РЧО

Рис. 1. Кінематична схема механізму управління РЧО ДП ДР1А

Як початкова і вхідна ланка механізму розглядається повзун 1. Його поточне положення $Z_{A i}$ (положення всіх рухомих ланок кінематичного ланцюга) визнача- 
ється переміщенням $S_{A i}$ виконавчої ланки електропневматичного модуля (ЕПМ), величина якого залежить від встановленої позиції контролера машиніста $i$. Величина частоти обертання $n_{K B}$ визначається положенням $\varphi_{5 i}$ важеля 5. Таким чином метою даного дослідження було отримання аналітичної залежності вигляду $\varphi_{5 i}=f\left(S_{A i}\right)$.

Вихідними даними в дослідженні є: закон руху початкової ланки $S_{A i}=f(i)$; довжини ланок $2 \ldots 5-l_{A B}, l_{B C}, l_{C D}, l_{D E}$, $l_{E F}$; відстань між осями обертання важелів 3 i $5-l_{X}$; відстань між паралельними площинами $X Z$, в яких обертаються важелі 3 і $5-l_{Y}$; відстань між віссю $Z$ і віссю руху повзуна $1-e$; вихідне положення точки $A$ $Z_{A 0}$.

Відповідно до методу проекцій замкнених векторних контурів на координатні осі дійсну кінематичну схему механізму доцільно подати у вигляді таких векторних контурів (рис. 2):

- плоского контуру $A B C K A$, що утворений векторами $\bar{l}_{A B}, \bar{l}_{B C}, \bar{Z}_{B}$ і $\bar{e}$, які розташовані в одній площині $X Z$;
- просторового контуру $C D E F C$, що утворений векторами $\bar{l}_{C D}, \bar{l}_{D E}, \bar{l}_{E F}$ і $\bar{l}_{F C}$.

Відповідно до цього розв'язання задачі також поділяється на два етапи:

- 3 розглядання контуру $A B C K A$ отримання аналітичної залежності вигляду $\varphi_{3 i}=f\left(S_{A i}\right)$;

- 3 розглядання контуру CDEFC отримання шуканої аналітичної залежності вигляду $\varphi_{5 i}=f\left(S_{A i}\right)$.

Умова замкненості контуру $A B C K A$

$$
\bar{l}_{A B}+\bar{l}_{B C}=\bar{Z}_{A i}+\bar{e} .
$$

Рівняння (1) в проекціях на координатні осі $Z$ i $X$

$$
\begin{gathered}
-l_{B C} \cdot Z_{B C i}-l_{A B} \cdot Z_{A B i}=-Z_{A i} \\
l_{B C} \cdot X_{B C i}+l_{A B} \cdot X_{A B i}=e
\end{gathered}
$$

де змінні $Z_{A B i}, Z_{B C i}, X_{A B i}, X_{B C i}$ напрямні косинуси кутів між векторами $\bar{l}_{A B}, \bar{l}_{B C}$ і осями координат $Z$ і $X$ (рис. 2), які підлягають визначенню.

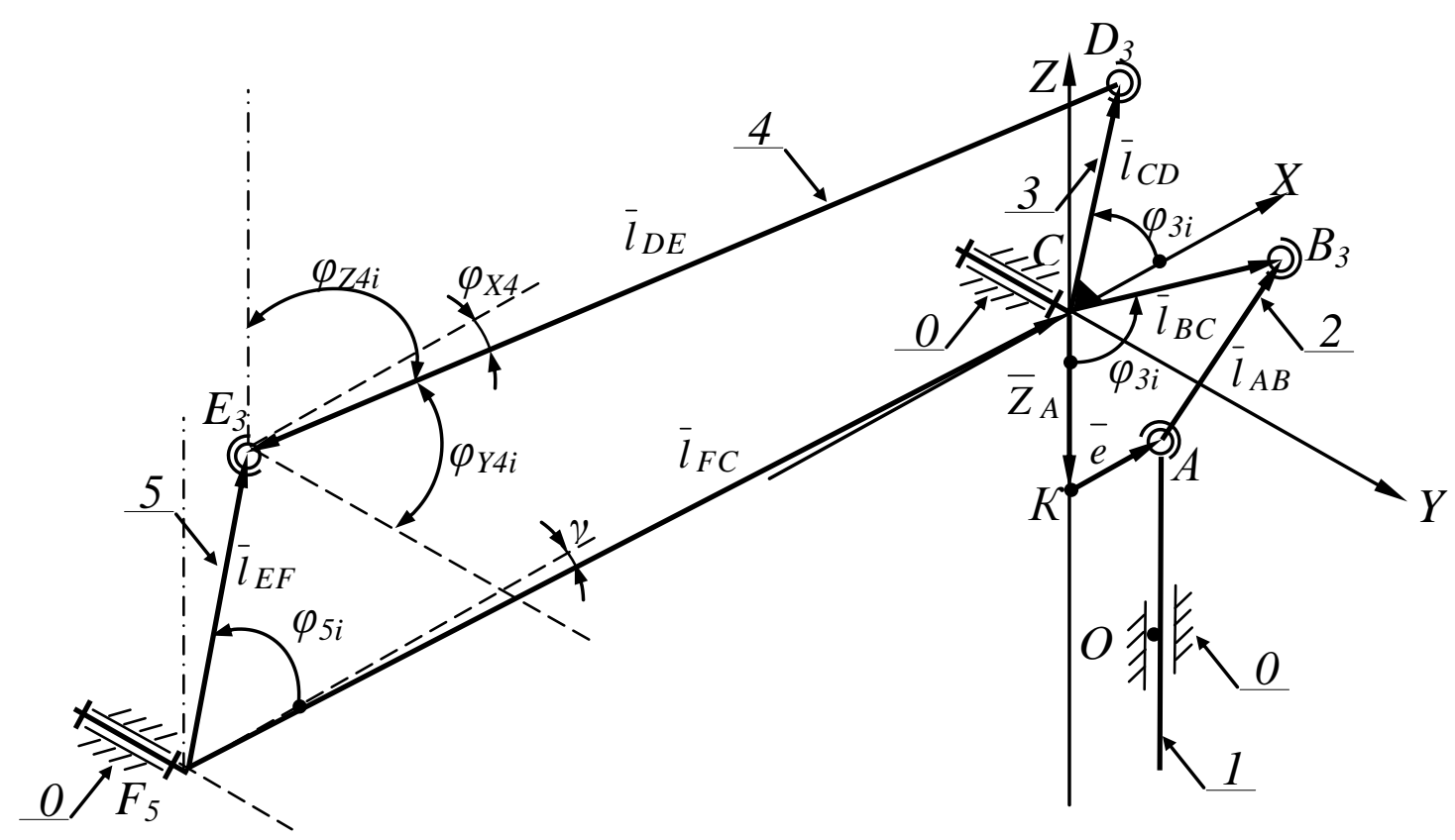

Рис. 2. Замінні векторні контури 
також використання відомих тригонометричних співвідношень між невідомими $Z_{A B i}, Z_{B C i}, X_{A B i}$ i $X_{B C i}$ дозволили сформувати систему з чотирьох рівнянь для їх визначення

$$
\left\{\begin{array}{l}
Z_{B C i}+\lambda_{2} \cdot Z_{A B i}=\lambda_{Z_{A i}} \\
X_{B C i}+\lambda_{2} \cdot X_{A B i}-\lambda_{e}=0 \\
X_{B C i}^{2}+Z_{B C i}^{2}=1 \\
X_{A B i}^{2}+Z_{A B i}^{2}=1
\end{array}\right.
$$

$$
B_{i}=-\frac{2 \cdot A_{i} \cdot \lambda_{Z_{A i}}}{\lambda_{Z_{A i}}^{2}+\lambda_{e}^{2}} ; \quad C_{i}=\frac{\left(A_{i}^{2}-\lambda_{e}^{2}\right)}{\left(\lambda_{Z_{A i}}^{2}+\lambda_{e}^{2}\right)} ; A_{i}=\frac{\lambda_{Z_{A i}}^{2}-\lambda_{2}^{2}+\lambda_{e}^{2}+1}{2}
$$

Для отримання розрахункових аналітичних залежностей при проведенні другого етапу досліджень уводились коефіцієнти $\lambda_{3}=l_{C D} / l_{D E} ; \quad \lambda_{5}=l_{E F} / l_{D E}$, $\lambda_{O}=l_{F C} / l_{D E}$. де $\lambda_{Z_{A i}}=\left(Z_{A O}-S_{A i}\right) / l_{B C}$;

$$
\lambda_{2}=l_{A B} / l_{B C} ; \lambda_{e}=e / l_{B C} \text {. }
$$

3 аналізу системи рівнянь (4) отримана формула для визначення поточних положень важеля 3

$$
\varphi_{3 i}=\arccos \left(-\frac{B_{i}}{2}-\sqrt{\frac{B_{i}^{2}}{4}-C_{i}}\right)
$$

де змінні

$$
\text { (4) }
$$




$$
\left\{\begin{array}{l}
\lambda_{0} \cdot X_{F C}+\lambda_{3} \cdot X_{C D i}+X_{D E i}-\lambda_{5} \cdot X_{E F i}=0 \\
\lambda_{0} Y_{F C}+Y_{D E i}=0 \\
\lambda_{3} \cdot Z_{C D i}+Z_{D E i}-\lambda_{5} \cdot Z_{E F i}=0 \\
X_{D E i}^{2}+Y_{D E i}^{2}+Z_{D E i}^{2}=1 \\
X_{E F i}^{2}+Z_{E F i}^{2}=1
\end{array}\right.
$$

3 аналізу системи рівнянь (8) отримана математична залежність для визначення поточних положень важеля 5

$$
\varphi_{5 i}=\arccos \left(-\frac{P_{i}}{2}-\sqrt{\frac{P_{i}^{2}}{4}-Q_{i}}\right)
$$

Складові рівняння (9) визначаються за наведеними нижче формулами

$$
P_{i}=-\frac{R_{i} \cdot\left\{R_{i}^{2}-\left[1-\left(\lambda_{0} \cdot Y_{F C}\right)^{2}-\left(\lambda_{3} \cdot Z_{C D i}\right)^{2}-\lambda_{5}^{2}\right]\right\}}{\lambda_{5} \cdot\left(R_{i}^{2}+\lambda_{3}^{2} \cdot Z_{C D i}^{2}\right)},
$$

де змінна $R_{i}=\lambda_{0} \cdot X_{F C}+\lambda_{3} \cdot X_{C D i}$;

$$
Q_{i}=\frac{\left\{R_{i}^{2}-\left[1-\left(\lambda_{0} \cdot Y_{F C}\right)^{2}-\left(\lambda_{3} \cdot Z_{C D i}\right)^{2}-\lambda_{5}^{2}\right]\right\}^{2}-\left(2 \cdot \lambda_{5} \cdot \lambda_{3} \cdot Z_{C D i}\right)^{2}}{4 \cdot \lambda_{5}^{2} \cdot\left(R_{i}^{2}+\lambda_{3}^{2} \cdot Z_{C D i}^{2}\right)}
$$

3 використанням отриманих математичних залежностей було проведено дослідження кінематики механічної системи регулювання швидкості ДП ДР1А для серійної конструкції просторового механізму управління РЧО. Результати такого дослідження наведені на рис. 3 у вигляді діаграм зміни переміщень повзуна 1 (початкової ланки) $S_{a i}$ і кутів оберту важеля 5 (вихідної ланки) $\varphi_{5 i}$ в залежності від встановленої позиції контролера машиніста $i$. Їх зіставлення 3 попередніми дослідженнями, в яких механізм управління РЧО розглядався як плоский, свідчать про суттєве (до 5\%) уточнення кутових переміщень вихідного важеля. У свою чергу це дозволяє уточнено оцінювати зміну $n_{K B}$ (до $15 \ldots 20$ об/хв) силової установки ДП ДР1А.

Висновки i перспективи подальшого використання. Розглянуті в статті особливості аналітичного дослідження, отримані математичні залежності дозволяють розраховувати уточнені кінематичні характеристики просторового механізму управління РЧО. Це забезпечує проведення пошукових досліджень 3 вибору раціональних геометричних параметрів ланок механічної системи регулювання швидкості 3 метою поліпшення тягових характеристик за умов підвищення техніко-економічних показників ДП ДР1А в експлуатації. 


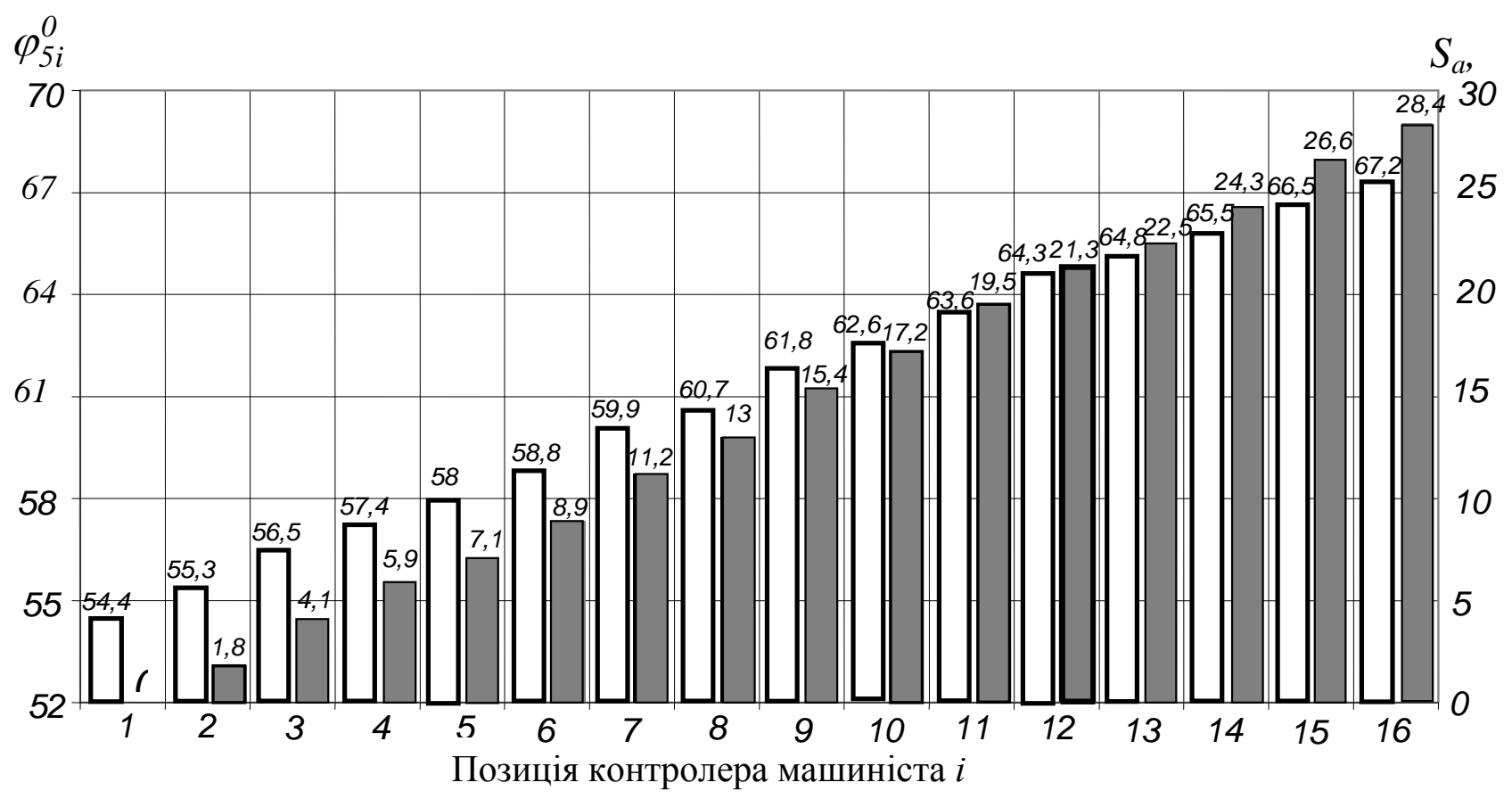

Рис. 3 Діаграми переміщень ланок механізму управління РЧО:

$$
\begin{aligned}
& \square \quad \text { - початкової ланки } S_{A i}=f(i) \text {; } \\
& \square \quad \text { - вихідної ланки } \varphi_{5 i}=f(i) .
\end{aligned}
$$

\section{Сиисок літератури}

1. Басов, Г.Г. Прогнозування розвитку дизель-поїздів для залізниць України [Текст] / Г.Г. Басов.- Харків: «Апекс +», 2004. - Ч. 1. - 240 с.

2. Залізничний транспорт України: Нормативна база [Текст]/ О.М.Роїна (упоряд.). - К.: KHT, 2005. -480 c.

3. Мороз, В.І. Дослідження характеристик функціонування електропневматичного модуля перетворення системи регулювання швидкості дизель-поїздів ДР1А [Текст] / B.I. Мороз, А.І. Біленький, О.В. Братченко // Зб. наук. праць. - Харків: УкрДАЗТ, 2006. Вип. 73. - С. $108-113$.

4. Братченко, О.В. Розрахункове дослідження важільного механізму керування регулятором швидкості дизеля М756Б [Текст] / О.В. Братченко, А.І. Біленький, В.Р. Войцехівський // Зб. наук. праць. - Харків: УкрДАЗТ, 2006. - Вип. 79. - С. 19 - 27.

5. Біленький, А.І. Результати експериментальної перевірки модернізованої системи регулювання швидкості дизель-поїзда ДР1А [Текст] / А.І. Біленький // Зб. наук. праць. Харків: УкрДАЗТ, 2007. - Вип. 81. - С. 131 - 138.

6. Мороз, В.І. Особливості математичного моделювання тягових характеристик дизельпоїзду ДР1А [Текст] / В.І. Мороз, О.В. Братченко, В.С.Тіщенко, А.І. Біленький// Зб. наук. праць. - Харків: УкрДАЗТ, 2007. - Вип. 86. - С. 122 - 128.

7. Зиновьев, В.А. Курс теории механизмов и машин [Текст] / В.А. Зиновьев. - М.: Наука, 1975. - 383 с. 
Ключові слова: залізничний рухомий склад, дизель-поїзд ДР1А, механічна система регулювання швидкості, просторовий механізм управління РЧО, кінематичні характеристики, аналітичні залежності.

\section{Анотаціï}

Відзначено, що одним з перспективних напрямків досягнення високого рівня експлуатаційних показників дизель-поїздів ДР1А $є$ поліпшення їх тягових характеристик за рахунок удосконалення конструкції механічної системи регулювання швидкості, основою якої $\epsilon$ просторовий механізм. Показано, що при проведенні пошукових досліджень актуальності набувають розрахунки кінематичних характеристик ланок просторового механізму, які можуть бути проведені на основі відповідних аналітичних залежностей. Висвітлено особливості аналітичного дослідження кінематичних характеристик механічної системи регулювання швидкості дизель-поїзда ДР1А, яке проводилось з використанням методу проекцій замкнених векторних контурів на осі координат. Подані результати уточненого розрахунку кінематичних характеристик ланок просторового механізму, що проводились 3 використанням отриманих аналітичних залежностей.

Отмечено, что одним из перспективных направлений достижения высокого уровня эксплуатационных показателей дизель-поездов ДР1А является улучшение их тяговых характеристик за счет усовершенствования конструкции механической системы регулирования скорости, основу которой составляет пространственный механизм. Показано, что при проведении поисковых исследований актуальными являются расчеты кинематических характеристик звеньев пространственного механизма, которые могут быть проведены на основе соответствующих аналитических зависимостей. Отражены особенности аналитического исследования кинематических характеристик механической системы регулирования скорости дизель-поезда ДР1А, которое проводилось с использование метода проекций замкнутых векторных контуров на оси координат. Представлены результаты уточненного расчета кинематических характеристик звеньев пространственного механизма, которые выполнялись с использованием полученных аналитических зависимостей.

Noted that one of the promising areas to achieve a high level of operational performance diesel trains DR1A is the improvement of the characteristics of the traction by improving the design of the mechanical speed control system, which was based on the spatial control mechanism. It is shown that during the exploratory research are relevant calculations kinematical characteristics links that may be conducted on the basis of HN-related analytical dependencies. Reflect the singularity of the kinematical characteristics of the analytical studies the mechanical speed control system of diesel trains DR1A with speciation control mechanism, which was conducted with the use of the Closed-loop vector projections on the coordinate axes. Presented the results of an updated calculation of the kinematical characteristics of links. 